\title{
DESINFECÇÃO DE EFLUENTE FINAL DE ABATEDOURO DE BOVINOS COM ÁCIDO PERACÉTICO PARA FINS DE REÚSO
}

Disinfection by peracetic acid for pos-treatment of wastewater of cattle slaughterhouse for reuse

Desinfección de efluente final de matadero de bovinos con ácido peracético para reutilización

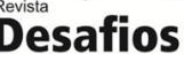

Artigo Original

\section{Grasiele Soares Cavallini ${ }^{* 1}$, Wesley Pereira Silva ${ }^{2}$, Mayara Ferreira Gonzaga ${ }^{3}$}

${ }^{1}$ Curso de Química Ambiental, Universidade Federal do Tocantins, Gurupi, Tocantins, Brasil.

*Correspondência: Universidade Federal do Tocantins, UFT - Rua Badejós, Lt. 07 Ch. 69/72 Zona Rural

77402970 - Gurupi, TO - Brasil - Caixa-postal: 66.e-mail grasiele@uft.edu.br

\section{RESUMO}

A bovinocultura é uma das principais atividades produtivas do agronegócio brasileiro, colocando o país no primeiro lugar em exportações de carne bovina do mundo. O grande número de abate de animais implica na geração de elevado volume de efluente líquido, sendo estimado um consumo de 2500 litros de água por animal abatido. Este efluente, além de rico em matéria orgânica, também apresenta microrganismos patogênicos provenientes da lavagem das vísceras e das fezes dos animais. A inativação destes microrganismos não ocorre por tratamento secundário, como lagoas de estabilização, a forma de tratamento mais empregada para este tipo de efluente, o que tem restringido possibilidades de reúso deste efluente. Assim, este trabalho investigou um desinfetante não clorado, o ácido peracético (APA), o qual possibilitou, além da desinfecção, a oxigenação do efluente. O tratamento terciário proposto teve o objetivo de melhorar a qualidade do efluente final para o seu possível reúso. A concentração de $5 \mathrm{mg} / \mathrm{L}$ de APA em um tempo de contato de 10 minutos foram suficientes para a adequação microbiológica exigida pelo Manual de reúso da EPA, para reúso agrícola restritivo. No entanto, a dosagem de $20 \mathrm{mg} / \mathrm{L}$ de APA, além de maior desinfecção, não proporciona aumento de DBO do efluente.

Palavras-chave: Tratamento terciário com ácido peracético, irrigação de pastagem, redução de DBO com APA.

\section{ABSTRACT}

Bovine farming is one of the main productive activities of Brazilian agribusiness, placing the country in the first place in beef exports in the world. The large number of slaughter of animals implies in the generation of high volume of liquid effluent, being estimated a consumption of 2500L of water per slaughtered animal. This effluent, in addition to being rich in organic matter, also presents pathogenic microorganisms from the viscera washing and feces of the animals. The necessary inactivation of these microorganisms does not occur through secondary treatment, such as stabilization ponds, the most used treatment for this type of effluent, restricting the possibilities of reuse of this effluent. For this reason, this work investigated a non-chlorinated disinfectant, peracetic acid (PAA), which allows, in addition to disinfection, oxygenation of the effluent. The proposed tertiary treatment had the objective of improving the quality of the final effluent for its possible reuse. The concentration of $5 \mathrm{mg} / \mathrm{L}$ PAA at a contact time of 10 minutes was sufficient for the microbiological suitability required by the EPA Reuse Manual for restrictive agricultural reuse. However, the dosage of $20 \mathrm{mg} / \mathrm{L} P A A$, in addition to greater disinfection, does not increase BOD of the effluent.

Keywords: Tertiary treatment with peracetic acid, pasture irrigation, BOD reduction with PAA.

\section{RESUMEN}


La bovocultura es una de las principales actividades productivas del agronegocio brasileño, colocando al país en el primer lugar en exportaciones de carne bovina del mundo. El gran número de abate de animales implica la generación de un elevado volumen de efluente líquido y se estima un consumo de $2500 \mathrm{~L}$ de agua por animal sacrificado. Este efluente, además de rico en materia orgánica, también presenta microorganismos patógenos provenientes del lavado de las vísceras y de las heces de los animales. La inactivación de estos microorganismos no ocurre por tratamiento secundario, como lagunas de estabilización, la forma de tratamiento más empleada para este tipo de efluente, restringiendo las posibilidades de reutilización de este efluente. Así, este trabajo investigó un desinfectante no clorado, el ácido peracético (APA), el cual posibilitó, además de la desinfección, la oxigenación del efluente. El tratamiento terciario propuesto tuvo el objetivo de mejorar la calidad del efluente final para su posible reutilización. La concentración de $5 \mathrm{mg} / \mathrm{L}$ de APA en un tiempo de contacto de 10 minutos fue suficiente para la adecuación microbiológica exigida por el Manual de reutilización de la EPA, para reutilización agrícola restrictiva. Sin embargo, la dosificación de 20mg/L de APA, además de una mayor desinfección, no proporciona aumento de DBO del efluente.

Descriptores: Tratamiento terciario con ácido peracético, riego de pastoreo, reducción de DBO con APA.

\section{INTRODUÇÃO}

A bovinocultura é uma das principais atividades produtivas do agronegócio brasileiro, e de acordo com a consulta do IBGE de 2012, é desenvolvida em todo o território nacional com 212,8 milhões de cabeças. De acordo com o Ministério de Agricultura, Pecuária e Abastecimento (MAPA) o Brasil possui o segundo maior rebanho mundial em número de cabeças, em número de abates e em produção de carne e desde 2008 ocupa o primeiro lugar em exportações de carne bovina (CLEMENTINO et al., 2015).

Além disso, o crescimento deste setor é promissor, segundo a FAO (Organização das Nações Unidas para Alimentação e Agricultura) e o OECD (Organização para Cooperação e Desenvolvimento Econômico) o aumento da renda e da população fará com que o consumo de carne aumente no mundo, principalmente em países em desenvolvimento, na Ásia e na América Latina (CNPC, 2015). De acordo com o Congresso Nacional da Carne de 2013, o consumo médio de carne por pessoa no Brasil em 2010 foi de 36kg por ano, e em 2013 subiu para 42kg.

Neste contexto, além do crescimento da produção e da economia baseada neste setor, também se deve avaliar o aumento na geração de efluentes líquidos provenientes dos abatedouros de bovinos. São estimados que 15 mil litros de águas residuárias possam ser gerados para cada tonelada de bovinos abatidos (SCARASSATI et al., 2003).

Este efluente além de rico em matéria orgânica, também apresenta microrganismos patogênicos proveniente das fezes dos animais ou ainda do conteúdo intestinal dos bovinos.

A desinfecção de efluentes contaminados por microrganismos patogênicos deve ser empregada, visando benefícios ambientais, econômicos e principalmente de saúde pública. Esta prática é defendida pelo Conselho Nacional de Meio Ambiente (CONAMA), o qual pela resolução 357/2005 (complementada pela Resolução 430/2011), descreve que, os efluentes provenientes de serviços de saúde e estabelecimentos nos quais haja despejos infectados com microrganismos patogênicos, como os abatedouros, só poderão ser lançados nos corpos hídricos após tratamento especial.

Embora de extrema importância a utilização do tratamento terciário, como a desinfecção, não é uma etapa realizada na maioria dos sistemas de tratamento de efluente, haja visto que tratamentos secundários, como lagoas aeradas, não promovem desinfecção eficiente. $\mathrm{O}$ que indica que mesmo tratado o potencial 
de contaminação microbiológica do efluente ainda oferece risco a população.

Neste trabalho o efluente final do sistema de tratamento de um abatedouro de bovinos será desinfetado utilizando ácido peracético (APA). O APA $\left(\mathrm{CH}_{3} \mathrm{COOOH}\right)$ é um oxidante utilizado em sínteses químicas, no branqueamento do papel, na medicina, na indústria alimentícia para limpeza de equipamentos e mais recentemente na área de saneamento ambiental. Sua utilização é alternativa ao cloro, a fim de evitar a formação de subprodutos carcinogênicos como os trihalometanos.

Para que esta utilização possa ser consolidada, estudos quanto a aplicação do APA são necessários, avaliando não só seu potencial desinfetante, com análises microbiológicas, mas também, os impactos gerados ao ambiente após a sua aplicação através de análises físico-químicas, logo que sua composição pode impactar no aumento da carga orgânica do efluente.

Um benefício adicional da desinfecção proposta é a liberação de oxigênio ao meio durante a sua ação. Visto que, a alta carga orgânica dos efluentes de abatedouros é um dos seus maiores problemas, a aplicação deste desinfetante pode ser uma saída para o aumento do oxigênio dissolvido do efluente final.

\section{MATERIAIS E MÉTODOS}

O efluente utilizado neste trabalho foi coletado de um abatedouro de pequeno porte com média de abate de 1200 cabeças de gado por mês. O efluente gerado é submetido por um sistema de tratamento composto por caixa de separação de gordura, decantador primário e quatro lagoas de estabilização. A aplicação do APA foi realizada no efluente final.

\section{Desinfecção do efluente com APA variando a dosagem e o tempo de contato}

Os ensaios avaliaram a eficiência do APA variando a dosagem do oxidante e o tempo de contato, nesta etapa as dosagens testadas foram de $5 ; 10$ e 20 $\mathrm{mg} / \mathrm{L}$ nos tempos de contato de 10 e 20 minutos para cada dosagem. As dosagens de APA foram preparadas a partir da solução comercial do APA de 15\%. Para desinfecção do efluente aplicou-se cada dosagem de APA em $500 \mathrm{~mL}$ de amostra, sob agitação em agitador magnético. Após o tempo de contato foram adicionadas duas gotas de Tiossulfato de Sódio 10\% para cada $250 \mathrm{~mL}$ de amostra, a fim de interromper ação desinfetante do APA.

Para análise bacteriológica utilizou-se a técnica da filtração em membranas, na qual foram filtrados $100 \mathrm{~mL}$ da amostra desinfetada, através de uma membrana de nitrato celulose estéril, quadriculada, de $47 \mathrm{~mm}$ de diâmetro e com porosidade de $0,45 \mu \mathrm{m}$ da marca SARTORIUS ${ }^{\circ}$, sendo a mesma disposta em placas de Petri contendo o meio de cultura seletivo e diferencial para coliformes HIMEDIA® e incubadas a $36^{\circ} \mathrm{C}$ por $24 \mathrm{~h}$ em estufa bacteriológica. Cada amostra foi incubada em três diferentes diluições para que o log de inativação do APA pudesse ser determinado com maior segurança. Sendo considerado o valor com maior densidade de microrganismos com o resultado final do experimento. A unidade utilizada é UFC/100mL (Unidade formadora de colônia por 100 $\mathrm{mL}$ da amostra) e a contagem foi realizada de forma manual.

O APA residual foi analisado antes da aplicação do tiossulfato de sódio, pelo método espectrofotométrico Chemetrics ${ }^{\circledR}$.

As metodologias físico-químicas e microbiológicas adotadas para a caracterização do efluente antes e após o tratamento seguem a descrição do Standard Methods for the Examination of Water and Wastewater (APHA, 1998). 
A constante de decaimento microbiano foi calculada pela Lei de Chick, a qual desconsidera a concentração do desinfetante, sendo então avaliada como cinética de primeira ordem, pois, para cada dosagem do desinfetante obtem-se um valor para $\mathrm{k}$. Entretanto, a constante $\mathrm{k}$ consideravelmente aumenta com o aumento da concentração do desinfetante.

A lei de Chick pode ser descrita graficamente por uma regressão linear (Figura 6), onde o eixo das ordenadas é representado por $\mathrm{Ln}\left(\mathrm{N} / \mathrm{N}_{0}\right)$ e das abscissas pelo tempo de contato, e a sua linearização que obrigatoriamente se inicia do ponto zero das ordenadas determina a constante de decaimento (k), representada pelo coeficiente angular da reta.

A equação 1 representa a Lei de Chick.

$$
\operatorname{Ln}\left(N / N_{0}\right)=-k t
$$

Onde: $\mathrm{k}=$ constante de decaimento bacteriano; $\mathrm{t}=$ tempo de contato; $\mathrm{N}_{0}=$ Número de colônias inicial; $\mathrm{N}=$ Número de colônias após a desinfecção.

Sendo esta equação válida nas condições: população homogênea de microrganismos; escoamento de pistão ou batelada de mistura completa; distribuição homogênea de desinfetante e microrganismos; concentração constante de desinfetante ao longo do tempo; e a constante $\mathrm{k}$ é valida para cada concentração de desinfetante, não sendo aplicada para outras concentrações (DANIEL et al., 2001).

Existem outros métodos cinéticos que poderiam ser aplicados para determinação da constante de decaimento em processos de desinfecção, porém os resultados obtidos neste trabalho permitem apenas a aplicação deste modelo.

\section{Ensaios de Demanda Bioquímica de Oxigênio (DBO) após aplicação do APA no efluente}

Pôde ser observado na Tabela 1, que os valores obtidos de E.coli são superiores ao recomendado pelo Manual de reúso de água da EPA (EPA, 2012).
Tabela 1. Comparação entre as características físicoquímicas e microbiológicas do efluente bruto e os valores recomendados para seu reúso agrícola restritivo.

\begin{tabular}{lcc}
\hline $\begin{array}{c}\text { Parâmetros físico- } \\
\text { químicos e } \\
\text { microbiológicos }\end{array}$ & $\begin{array}{c}\text { Resultados } \\
\text { obtidos }\end{array}$ & $\begin{array}{c}\text { Valores } \\
\text { recomendados pela } \\
\text { EPA para reúso } \\
\text { agrícola restritivo* }\end{array}$ \\
\hline $\mathrm{pH}$ & 7,4 & $6,0-9,0$ \\
\hline Sólidos Totais (mg/L) & 444 & Não descrito \\
\hline $\begin{array}{l}\text { Sólidos Suspensos } \\
\text { Totais (mg/L) }\end{array}$ & - & $\leq 30$ \\
\hline DBO (mg/L) Totais & $2,310^{6}$ & Não descrito \\
\hline $\begin{array}{l}\text { Coliformes } \\
\text { (CT) (UFC/100mL) }\end{array}$ & $1,910^{3}$ & $\leq 200$ \\
\hline E. coli (UFC/100mL)
\end{tabular}

* Manual de reúso de água da EPA, 2012.

Visando o aproveitamento desse efluente para fins de irrigação restritiva as lagoas de estabilização são consideradas como um dos melhores métodos para tal tratamento, entretanto, observou-se a necessidade de um sistema de pós-tratamento para maior remoção de patógenos.

Nesta etapa foram adicionadas diferentes concentrações do APA $(1,5,10,15$ e $20 \mathrm{mg} / \mathrm{L})$ no efluente e em seguida o ensaio de DBO foi realizado. Somente as amostras nas dosagens de 5, 10 e $20 \mathrm{mg} / \mathrm{L}$ foram realizados em duplicata. Uma amostra sem APA foi realizada para que a eficiência pudesse ser calculada. As análises de DBO foram realizadas pelo método respirométrico, em um analisador de DBO da marca Aqua Lityc, modelo AL606.

\section{RESULTADOS E DISCUSSÃO}

\section{Ensaio preliminar para caracterização do efluente}

$\mathrm{O}$ efluente final do abatedouro em estudo é utilizado para irrigação de pastagens, porém sem controle bacteriológico. Devido à ausência de uma legislação específica para reúso no Brasil, utilizou-se o Manual de reúso de água da EPA (EPA, 2012), para avaliar se esta possibilidade de aplicação, do efluente sem desinfecção, seria recomendável (Tab. 1). Este manual descreve esta aplicação como reúso agrícola restritivo, podendo ser utilizado para irrigação de 
culturas processadas antes do consumo humano ou não consumidas pelos seres humanos.

O reúso de efluentes contendo microrganismos patógenos é classificado como uma alternativa de riscos elevados, o que os torna inoportuno sem devido tratamento, entretanto em algumas regiões o tratamento necessário não é economicamente viável para modo de reúso que é almejado (HESPANHOL, 2002).

Segundo Rezende (2010) a utilização de efluentes contaminados para o reúso agrícola pode implicar em: contaminação de consumidores de alimentos contaminados com organismos patogênicos e/ou substâncias químicas tóxicas, contaminação direta dos trabalhadores, contaminação do público por aerossóis e contaminação de consumidores de animais que se alimentam de pastagens irrigadas, ou que sejam criados em lagoas contaminadas.

A partir dos resultados preliminares, pode-se observar que a desinfecção como forma de póstratamento se faz necessária neste sistema, justificando o trabalho proposto para o abatedouro estudado.

\section{Ensaios de desinfecção do efluente com ácido peracético}

Os resultados obtidos nos ensaios de desinfecção com APA em diferentes dosagens $(5,10$ e $20 \mathrm{mg} / \mathrm{L}$ ) e tempos (10 e 20 minutos) são apresentados na Tabela 2.

Tabela 2. Inativação de CT e E. coli em diferentes dosagens e tempos de contato.

\begin{tabular}{cccc}
\hline $\begin{array}{c}\text { APA } \\
(\mathrm{mg} / \mathrm{L})\end{array}$ & $\begin{array}{c}\text { Tempo de } \\
\text { contato (min.) }\end{array}$ & $\begin{array}{c}\text { E.coli } \\
(\mathrm{UFC} / 100 \mathrm{~mL})\end{array}$ & $\begin{array}{c}\mathrm{CT} \\
(\mathrm{UFC} / 100 \mathrm{~mL})\end{array}$ \\
\hline 0 & 0 & 1910 & 2300000 \\
5 & 10 & 20 & $\mathrm{AF}^{*}$ \\
5 & 20 & $<1$ & $\mathrm{AF}^{*}$ \\
10 & 10 & 10 & 467000 \\
10 & 20 & $<1$ & 303000 \\
20 & 10 & $<1$ & 600 \\
20 & 20 & $<1$ & 250 \\
\hline
\end{tabular}

*AF=acima da faixa de contagem.
Os resultados obtidos demonstraram que a dosagem de $5 \mathrm{mg} / \mathrm{L}$ de APA em tempo de contato de 10 minutos atinge o valor abaixo de 200 coliformes fecais (E. coli) em $100 \mathrm{ml}$, recomendado pelo Manual de reúso da EPA (2012). Houve também uma maior remoção tanto para E. coli quanto para CT com o aumento da concentração e do tempo de contato do APA, entretanto o aumento do tempo de contato após a obtenção da concentração mínima necessária é quase irrelevante, e pode-se observar que a eficiência do desinfetante diminui com o aumento do tempo, como descrito pela Lei de Chick. A Figura 1 ilustra a comparação das dosagens 10 e $20 \mathrm{mg} / \mathrm{L}$ de APA em um mesmo tempo de contato de 10 minutos.

Figura 1. À esquerda da foto, a amostra após aplicação de APA $10 \mathrm{mg} / \mathrm{L}$ com tempo de contato de 10 minutos na diluição $10^{-1}$. À direita da foto, a amostra após aplicação de APA $20 \mathrm{mg} / \mathrm{L}$ com tempo de contato de 10 minutos na diluição $10^{-1}$.

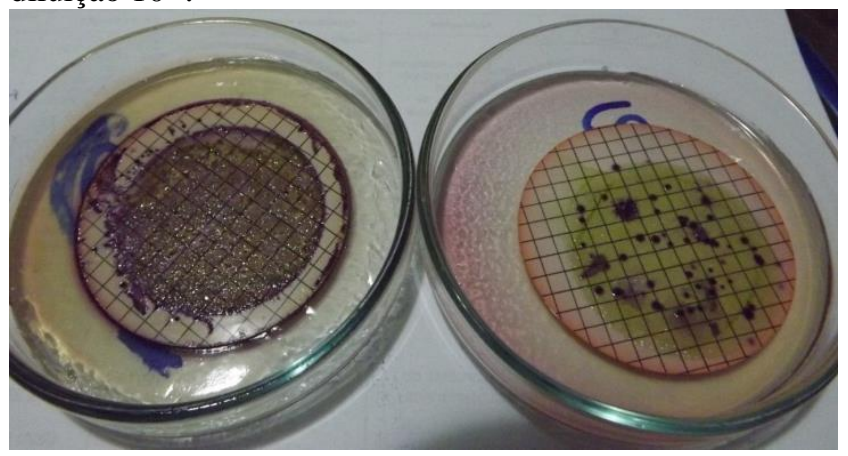

Vale ressaltar que nessas placas foram filtrados $10 \mathrm{~mL}$ de amostra (diluição $10^{-1}$ ) e não $100 \mathrm{~mL}$, devido a grande quantidade de microrganismos. Ou seja, as placas estão sendo representadas por apenas $10 \%$ do numero real de colônias. Esta interpretação é interessante, para que a eficiência de desinfecção devido ao aumento do desinfetante seja subestimada.

A Figura 2 apresenta os resultados apresentados na Tabela 2, convertidos em eficiência de remoção em unidades logarítmicas. Esta unidade é usualmente empregada para avaliar a eficiência na 
inativação de microrganismos indicadores de contaminação, devido ao grande número de microrganismos em efluentes contaminados.

Figura 2. Eficiência de inativação de CT e E. coli.

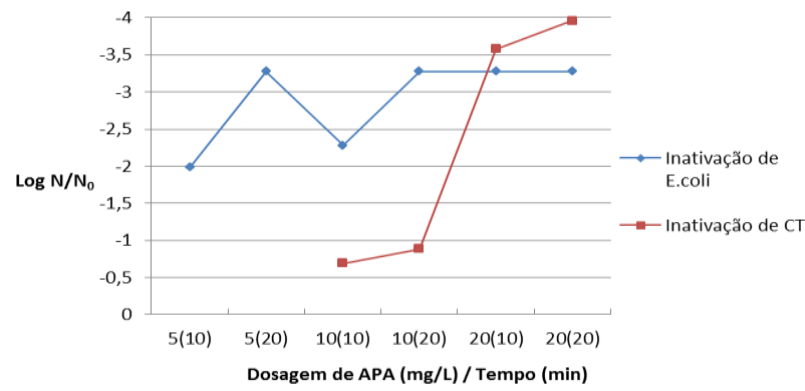

$\mathrm{N}=$ número de colônias finais; $\mathrm{N}_{0}=$ número de colônias iniciais.

Pode-se observar que na dosagem de $5 \mathrm{mg} / \mathrm{L}$ de APA foram necessários tempos de contato acima de 10 minutos para inativação total de E. coli. O residual de APA foi medido apenas na dosagem de $5 \mathrm{mg} / \mathrm{L}$ após 10 minutos, isso porque, a ausência de APA residual, não permitiria o ensaio com tempo de contato de 20 minutos. O valor residual obtido foi de $0,14 \mathrm{mg} / \mathrm{L} \mathrm{de}$ APA.

Quanto ao tempo de contato, se observou que em dosagens menores a contribuição do tempo se torna mais significativa.

Quanto a inativação de coliformes totais, a dosagem de $20 \mathrm{mg} / \mathrm{L}$ no tempo de contato de 20 minutos alcançaram valores bem próximos de 4 logs de inativação, o que equivale a 99,989\% de remoção dos microrganismos. Os coliformes totais são microrganismos mais dificilmente inativados e a presença de sólidos na amostra podem servir de proteção para essas bactérias, consequentemente, aumentam o consumo do oxidante, e diminuem seu potencial desinfetante.

Considerando os valores recomendados pela EPA para reutilização agrícola restritivo, apresentado na tabela 2, a aplicação de APA em concentrações de 5 mg/L já seriam suficientes para a utilização segura do efluente.
Além dessa aplicação, considerando o parâmetro microbiológico recomendado pela EPA (EPA, 2012), o efluente tratado com 5 mg/L de APA e tempo de contato de 20 minutos poderia ser empregado em: Reúso urbanos não restritivo, Reúso urbano restritivo, Reúso agrícola não restritivo, Represamento, Represamento restritivo, Reúso ambiental e Reúso industrial. Excluindo apenas as categorias de reúso mais rigorosas que abrangem a utilização de no abastecimento de consumo humano, como, Reabastecimento de águas subterrâneas, Reutilização não potável e reúso potável direto.

Vale ressaltar, que o parâmetro microbiológico foi utilizado como referencia para o enquadramento de reúso por se tratar do estudo de um desinfetante alternativo. Porém, é de interesse para os processos de desinfecção que o oxidante não contribua de forma negativa para as condições finais do efluente tratado. Sendo o APA um ácido fraco, não foi observado diminuição significativo de $\mathrm{pH}$, o qual se apresentou sempre superior a 7, quanto ao parâmetro DBO, sua possível interferência foi avaliada individualmente a seguir.

\section{Contribuições da aplicação do ácido peracético no efluente quanto ao parâmetro DBO}

A matéria orgânica é um fator relevante a ser considerada diante do estudo, pois quanto maior for a quantidade de matéria orgânica biodegradável maior será o consumo de oxigênio e consequentemente maior a DBO, ocasionando então uma redução no potencial de autodepuração do corpo hídrico receptor (JORDÃO et al., 2007).

De acordo com Kitis (2004) a dosagem de 5 mg/L de APA contribui para um aumento da DQO (demanda química de oxigênio) de $14 \mathrm{mg} / \mathrm{L}$, devido a presença do ácido acético. Sendo o ácido acético um composto biodegradável, pode-se prever, 
teoricamente, que a DBO também aumente em 14 $\mathrm{mg} / \mathrm{L}$ a cada $5 \mathrm{mg} / \mathrm{L}$ de APA adicionado. Estes valores teóricos podem ser utilizados de forma comparativa a DBO encontrada do efluente final, para que o comportamento real do APA possa ser avaliado.

A Tabela 3 apresenta os resultados da DBO5 obtidos após a aplicação do APA e os valores teóricos esperados, ou seja, $14 \mathrm{mg} / \mathrm{L}$ a cada $5 \mathrm{mg} / \mathrm{L}$ de APA adicionado (KITIS, 2004).

Tabela 3. Valores de DBO após aplicação do APA.

\begin{tabular}{ccc}
\hline $\begin{array}{c}\text { Dosagem de } \\
\text { APA }(\mathrm{mg} / \mathrm{L})\end{array}$ & $\begin{array}{c}\mathrm{DBO}_{5} \\
(\mathrm{mg} / \mathrm{L})\end{array}$ & $\begin{array}{c}\mathrm{DBO}_{5} \text { teórica } \\
(\mathrm{mg} / \mathrm{L})\end{array}$ \\
\hline 0 & $66 \pm 5,6$ & 70 \\
1 & 65 & 73 \\
5 & 86 & 84 \\
10 & $68 \pm 17,0$ & 98 \\
15 & 77 & 112 \\
20 & $60 \pm 18,4$ & 126 \\
\hline
\end{tabular}

Pode-se observar que a adição do APA contribuiu para o aumento da DBO, porém, de forma inferior ao esperado teoricamente. $\mathrm{O}$ melhor exemplo disso foi observado na dosagem de $20 \mathrm{mg} / \mathrm{L}$, a qual praticamente, manteve o valor da DBO do efluente bruto. Este resultado é importante, pois demonstra que a geração de oxigênio atribuída à decomposição do APA acontece de forma lenta e o oxigênio formado pode ser incorporado no meio liquido e aproveitado pelas bactérias aeróbicas. Através dos valores teóricos é possível observar que houve diminuição da DBO, superior a $40 \%$ do que era esperado, quando a dosagem de $20 \mathrm{mg} / \mathrm{L}$ de APA foi aplicada. Ou seja, a geração de oxigênio foi suficiente para degradação da carga orgânica gerada pela aplicação do APA.

Vale ressaltar que se a formação de oxigênio fosse rápida, a saturação do oxigênio na água seria atingida e o oxigênio seria liberado para atmosfera, o que não seria interessante para o processo de autodepuração.

Dosagens superiores de APA poderiam ser testadas, para que a remoção da DBO fosse ainda maior, porém, a falta de dados da ecotoxicidade do APA não asseguram que dosagens elevadas não inibiram a ação das bactérias, acarretando em um resultado da redução de DBO falso.

O ensaio de DBO, conforme o procedimento padrão de analise (APHA, 1998) corresponde a incubação da amostra por cinco dias, pois estima-se que neste período, a degradação da matéria orgânica biodegradável pelas bactérias seja de aproximadamente $80 \%$. Considerando a liberação lenta de oxigênio na decomposição do APA, realizouse um ensaio de DBO de 5 e de 10 dias, isto porque, com a extensão do período de análise, mais oxigênio poderia ser gerado e a DBO poderia ser menor. Os resultados obtidos foram apresentados na Tabela 4.

Tabela 4. Valores de $\mathrm{DBO}_{10}$ após aplicação do APA.

\begin{tabular}{cccc}
\hline $\begin{array}{c}\text { Dosagem de } \\
\text { APA }(m g / L)\end{array}$ & $\begin{array}{c}\mathrm{DBO}_{5} \\
(\mathrm{mg} / \mathrm{L})\end{array}$ & $\begin{array}{c}\mathrm{DBO}_{5} \text { teórica } \\
(\mathrm{mg} / \mathrm{L})\end{array}$ & $\begin{array}{c}\mathrm{DBO}_{10} \\
(\mathrm{mg} / \mathrm{L})\end{array}$ \\
\hline 0 & $66 \pm 5,6$ & - & 65 \\
10 & $68 \pm 17,0$ & 90 & 79 \\
20 & $60 \pm 18,4$ & 118 & 54 \\
\hline
\end{tabular}

Neste novo ensaio observou-se que a DBO de cinco dias apresentou resultados ainda melhores para a dosagem acima de $10 \mathrm{mg} / \mathrm{L}$, em relação aos resultados apresentados na Tabela 3 , ou seja, menores que amostra bruta. Quanto a DBO de 10 dias, a qual apresentou valores superiores por corresponder a um período maior de incubação, foram observados valores de DBO menores para a dosagem de $20 \mathrm{mg} / \mathrm{L} \mathrm{em}$ relação a amostra bruta. E assim, se observa mais uma vez, que dosagens de APA com concentração residuais maiores possibilitam o fornecimento de oxigênio e uma redução da DBO do efluente. A hipótese de toxicidade as bactérias não pode ser descartada sem a realização de ensaio ecotoxicológico.

Quanto a possibilidade de reutilização do efluente, em relação ao parâmetro $\mathrm{DBO}$, conclui-se que dosagens de $20 \mathrm{mg} / \mathrm{L}$ não confere aumento 
significativo na DBO final do efluente tratado, e que melhorias nos sistema de tratamento secundário de abatedouro poderiam favorecer a aplicação do desinfetante.

\section{Cálculo da constante de decaimento no processo de desinfecção proposto}

A obtenção da cinética do desinfetante é de extrema importância para o dimensionamento e avaliação do sistema de desinfecção. O modelo utilizado para este cálculo segue a Lei de Chick, a qual estabelece o valor de $\mathrm{k}$ através da linearização dos pontos obtidos por $\mathrm{Ln}\left(\mathrm{N} / \mathrm{N}_{0}\right)$ em função do tempo de contato.

Sendo a equação da reta correspondente $\mathrm{a} \mathrm{y}=$ $\mathrm{ax}+\mathrm{b}$, a constante de decaimento $\mathrm{k}$ é equivalente ao valor do coeficiente angular da reta (a). Cada dosagem apresenta um valor de $\mathrm{k}$ para E.coli e outro para coliformes totais, os valores são apresentados na Tabela 5.

Tabela 5. Valores das constantes de decaimento no processo de desinfecção.

\begin{tabular}{|c|c|c|c|c|c|}
\hline & $\begin{array}{c}\text { APA } \\
(\mathrm{mg} / \mathrm{L})\end{array}$ & $\begin{array}{c}\text { Tempo de } \\
\text { contato } \\
\text { (min) }\end{array}$ & $\begin{array}{c}N_{0} \\
(\mathrm{UFC} / \\
100 \mathrm{~mL})\end{array}$ & $\begin{array}{c}\mathrm{N} \\
(\mathrm{UFC} / \\
100 \mathrm{~mL})\end{array}$ & $\mathrm{k}$ \\
\hline \multirow{6}{*}{ E. coli } & 5 & 10 & 1910 & 20 & \multirow{2}{*}{0,393} \\
\hline & 5 & 20 & 1910 & $<1$ & \\
\hline & 10 & 10 & 1910 & 10 & \multirow{2}{*}{0,407} \\
\hline & 10 & 20 & 1910 & $<1$ & \\
\hline & 20 & 10 & 1910 & $<1$ & \multirow{2}{*}{0,453} \\
\hline & 20 & 20 & 1910 & $<1$ & \\
\hline \multirow{4}{*}{$\begin{array}{c}\text { Coliformes } \\
\text { Totais }\end{array}$} & 10 & 10 & 2300000 & 467000 & \multirow{2}{*}{0,113} \\
\hline & 10 & 20 & 2300000 & 303000 & \\
\hline & 20 & 10 & 2300000 & 600 & \multirow{2}{*}{0,530} \\
\hline & 20 & 20 & 2300000 & 250 & \\
\hline
\end{tabular}

Pode-se observar na Tabela 5, que para ambos os microrganismos avaliados, E. coli e CT, o aumento da concentração e do tempo de contato contribuiu para a inativação, essa é uma característica própria de cada desinfetante, podendo haver desinfetantes em que a desinfecção ocorre de forma imediata e o tempo de contato não seja tão significante, ou ainda o aumento da concentração supra a necessidade de um grande tempo de contato. No entanto, a menor concentração do desinfetante deve ser priorizada, para evitar à formação de subprodutos ou toxicidade a biota. Conforme, descrito por Daniel et al. (2001) a constante de decaimento aumenta com o aumento da concentração do desinfetante.

Os valores de $\mathrm{k}$ apresentados na Tabela 6 foram obtidos pela linearização dos dados no gráfico apresentado na Figura 3. Para concentração de $5 \mathrm{mg} / \mathrm{L}$ de APA o ensaio correspondente a coliformes totais, ultrapassou o número de colônias passíveis de contagem, por isso a constante de decaimento não pode ser calculada.

Figura 3. Representação da constante de decaimento para E.coli e CT nas concentrações de 5; 10 e $20 \mathrm{mg} / \mathrm{L}$ de APA.

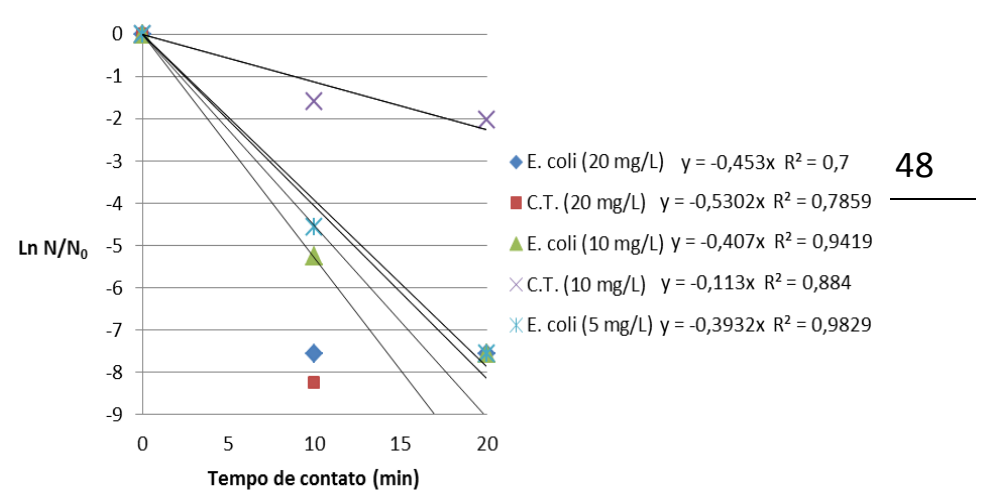

De acordo com a Lei de Chick, a qual não considera a variação da concentração do desinfetante durante a desinfecção, pôde-se estabelecer as constantes de decaimento de microrganismos, as quais poderiam ser utilizadas em escala piloto ou real. Modelos mais ajustados como Chick-Watson e Hom não puderam ser calculados, pois exigem determinação de residual a cada tempo de contato e essas análises não foram realizadas em todas estas etapas deste trabalho. 


\section{CONCLUSÃO}

Pode-se concluir que o efluente de abatedouro após os tratamentos primários (caixa de gordura e decantador primário) e secundários (lagoas de estabilização em série) não oferece qualidade microbiológica suficiente para ser utilizado na irrigação de pastagem. Com isso a etapa de desinfecção necessita ser incluída para uma aplicação mais segura, tanto para os animais que se alimentam do pasto, quanto para a proteção de lençóis freáticos devido à possibilidade de infiltração no solo. Cabe ressaltar que a região de Gurupi utiliza frequentemente poços como fonte de água para abastecimento e muitas vezes sem nenhum tratamento a essa realidade não se restringe as áreas rurais.

Quanto a qualidade microbiológica foi observado que mesmo na menor dosagem avaliada (5 mg/L de APA em 10 minutos) o efluente tratado apresentou condições microbiológicas suficientes para irrigação de pastagem e ainda outras aplicações que se enquadrem nas categorias de Reúso urbano não restritivo, Reúso urbano restritivo, Reúso agrícola não restritivo e restritivo, Represamento, Represamento restritivo, Reúso ambiental e Reúso industrial.

A dosagem de $20 \mathrm{mg} / \mathrm{L}$ em um tempo de contato de 20 minutos são mais recomendadas para o efluente estudado, devido a maior inativação de microrganismos, a qual atingiu inativação de $\mathrm{E}$.coli, e um valor final de coliformes totais de 250 UFC/100 $\mathrm{mL}$, quase alcançando o limite de $200 \mathrm{UFC} / 100 \mathrm{~mL}$ estabelecido para reúso em Reabastecimento de águas subterrâneas não potável, as categorias mais nobres de reutilização, segundo EPA.

Dosagens superiores não foram testadas, devido à ausência de ensaios ecotoxicológicos que atestassem a segurança destas concentrações. O que justifica a utilização das dosagens utilizadas sem ensaios ecotoxicológicos é o rápido consumo do oxidante e, consequentemente, a baixa concentração residual no efluente tratado.

No entanto, o custo do APA é aproximadamente 4 a 5 vezes maior do que o hipoclorito de sódio, porém um aumento na sua demanda poderia reduzir os custos de produção e viabilizando sua aplicação.

\section{AGRADECIMENTO}

O presente trabalho foi realizado com o apoio do Conselho Nacional de Desenvolvimento Científico e Tecnológico -CNPq - Brasil. O desenvolvimento desta pesquisa contou com benefícios do Programa Novos Pesquisadores da UFT (Propesq/UFT). Agradecemos também a Thech Desinfecção Ltda pelo apoio à pesquisa.

Todos os autores declararam não haver qualquer potencial conflito de interesses referente a este artigo.

\section{REFERÊNCIAS}

APHA / AWWA / WEF. Standard Methods of the Examination of Water and Wastewater. 20th ed. APHA (American Public Health Association) CDROM. USA, 1998.

CLEMENTINO, I. J.; PIMENTA, C. L. R. M.; FERNANDES, L. G.; BEZERRA, C. S.; ALVES, C. J.; DIAS, R. A.; AMAKU, M.; FERREIRA, F.; TELLES, E. O.; GONÇALVES, V. S. P.; FERREIRA NETO, J. S.; AZEVEDO, A. S. Caracterização da pecuária bovina no Estado da Paraíba, Nordeste do Brasil. Semina: Ciências Agrárias, Londrina, v. 36, n. 1, p. 557-570, jan./fev. 2015.

CNPC (Conselho Nacional de Pecuária de Corte). Pecuária traz possibilidades de um futuro melhor. Publicado em 23/03/2015. Disponível em: http://www.cnpc.org.br/news1.php?ID=8178.

Acessado em 12 de abril de 2015.

CONAMA (Conselho Nacional de Meio Ambiente) Resolução ${ }^{\circ} 357$ de 17 de março de 2005. Dispõe sobre a classificação dos corpos de água e diretrizes ambientais para o seu enquadramento, bem como estabelece as condições e padrões de lançamento de efluentes, e dá outras providências. Disponível em: 
<http://www.mma.gov.br/port/conama/res/res05/res3

5705.pdf >. Acessado em: 23 jun. 2010.

DANIEL, L. A.; BRANDÃO, C. C. S.; GUIMARÃES, J. R.; LIBÂNIO, M.; DE LUCA, S. J. Métodos Alternativos de Desinfecção da Água: Processos de Desinfecção e Desinfetantes Alternativos na Produção de Água Potável. $1^{\circ}$ Edição. São Paulo: RiMa Artes e Textos, 2001. 139p.

EPA (United States Environment Protection Agency). Manual para reúso de água. EPA/ 600/R - 12/618, 2012.

HESPANHOL, I. Potencial de Reuso de Água no Brasil Agricultura, Indústria, Municípios, Recarga de Aquíferos. RBRH - Revista Brasileira de Recursos Hídricos, v.7, p.75-95, 2002.

JORDÃO, C. P.; RIBEIRO, P. R. da S; MATOS, A. T. de; FERNANDES, R. B. A. Aquatic contamination of the Turvo Limpo river basin at the Minas Gerais state, Brazil. Journal of the Brazilian Chemical Society, v. 18, n. 1, p.116 - 125, 2007.

KITIS, M. Disinfection of wastewater with peracetic acid: a review. Environment International, v. 30, p. 47-55, 2004. 